\title{
DIARRHEA ASSOCIATED WITH ROTAVIRUS IN RURAL GUATEMALA: A LONGITUDINAL STUDY OF 24 INFANTS AND YOUNG CHILDREN*
}

\author{
RICHARD G. WYATT, ROBERT H. YOLKEN, JUAN J. URRUTIA, LEONARDO MATA, \\ HARRY B. GREENBERG, ROBERT M. CHANOCK, AND ALBERT Z. KAPIKIAN \\ Laboratory of Infectious Diseases, National Institute of Allergy and Infectious Diseases, \\ National Institutes of Health, Bethesda, Maryland 20014, Instituto de Nutrición de \\ Centro America y Panamá, Guatemala City, Guatemala, and Instituto de Investigaciones \\ en Solid, Universidad de Costa Rica, San Jose, Costa Rica
}

\begin{abstract}
A population of 24 infants and young children followed prospectively during the first 3 years of life was studied for the occurrence of rotavirus infection by using enzymelinked immunosorbent assay to detect virus in stools. Infection with rotavirus was associated with $26(14.2 \%)$ of 183 selected diarrhea! episodes. Twenty of the 24 infants and young children had diarrhea associated with rotavirus on at least one occasion and six had two such episodes. Rotavirus infection was documented in over 50\% of the dehydrating episodes studied, thus further indicating the importance of rotavirus in this population.
\end{abstract}

Rotavirus, a member of the reoviridae family, has emerged as a major pathogen associated with diarrhea! illness among infants and young children from many parts of the world." z Populations most frequently studied have been patients hospitalized with diarrhea! illness, and it is now important to define the natural history of rotavirus diarrhea among non-hospitalized cases, especially in less developed countries where morbidity and mortality associated with diarrheal disease are great. ${ }^{21}$ This survey indicates the importance of rotavirus diarrhea among a small population of infants and young children followed longitudinally in a rural Guatemalan village.

\section{MATERIALS AND METHODS}

Prospective studies of health and growth of children were carried out previously in the Guatemalan highland village of Santa Maria Cauqué.* Stool specimens were collected as a part of the studies on a weekly basis from a cohort of 45 children for purposes of defining the pattern of intestinal colonization and of studying enteric disease $\mathrm{a}^{\prime}$.

One hundred and eighty-three diarrheal episodes, which occurred between 1964 and 1967 in

Accepted 2 September 1978.

*Address reprint requests to Richard G. Wyatt, National Institutes of Health, Building 7, Room 105, Bethesda, Maryland 20014.
24 children of the original cohort of 45 , were selected for this study. Diarrhea was defined as four or more diarrheal stools per 24-hour period. Five hundred and fifty-seven stool samples, collected where possible before, during, and after diarrhea, were studied in sequence. Only diarrheal episodes occurring during the first 3 years of life were chosen for purposes of the present study, and episodes associated with known enteric pathogens, i.e. Shigella, Salmonella, enteropathogenic E. coli, or acute parasitic infection, were excluded. Stools were prepared as previously described and stored at $-60^{\circ} \mathrm{C}$ pending further study.' These same fecal preparations were studied previously for the presence of bacteria, parasites, and viruses ( enterovirus and adenovirus) as described. ${ }^{4}$ All stool preparations were examined for rotavirus in the current study by the enzyme-linked immunosorbent assay (ELISA) as adapted for the detection of rotavirus with additional modifications. ${ }^{\circ}$ Samples were tested undiluted or at an approximate 1:10 dilution where volume was small in 22 samples. All samples yielding a $\mathrm{P} / \mathrm{N}$ of greater than 2.0 were verified as positive in a blocking test ? Additionally, 79 diarrhea! samples from 11 of the 24 cohort children were also studied using negative stain electron microscopy (EM) on un-concentrated stool suspensions. Single selected diarrheal samples from 154 different episodes not associated with rotavirus were also tested for Norwalk viral antigens using radioimmunoassay (RIA) as described elsewhere. ${ }^{\circ}$ 
TABLE 1

Comparison of ensyme-linked immunosorbent assay (ELISA) and negative stain electron microscopy (EM) detection of rotavirus in 79 diarrheal stools*

\begin{tabular}{ccc}
\hline $\begin{array}{c}\text { Rotavirus detected } \\
\text { using EM }\end{array}$ & \multicolumn{2}{c}{ Rotavirus detected using ELISA } \\
\cline { 2 - 3 } & Yes & No \\
\hline Yes & 7 & 0 \\
No & 4 & 68 \\
\hline
\end{tabular}

* A single diartheal stool was chosen for study from each of 79 episodes of diarrheal illness occurring aunong 11 children.

Clinical records on the 24 cohort children were examined to determine the frequency of vomiting and dehydration (as determined by clinical observation) during the 183 diarrheal episodes studied for rotavirus. For purposes of comparison, records on all diarrheal episodes, totalling 345 during the same 3-year study period from the 24 children, were examined to determine the overall frequency of vomiting and dehydration.

\section{RESULTS}

Between 3 and 15 diarrheal episodes were studied from each of the 24 cohort children who ranged in age from 1-36 months at the time of illness. Rotavirus was detected in diarrheal stools collected during 26 (14.2\%) of 183 episodes. In addition, rotavirus was detected in $5(2.7 \%)$ stool samples obtained prior to or following the 183 diarrheal illnesses, but not in the acute diarrheal sample itself. Of the 24 cohort children studied, 20 had at least one episode of diarrhea associated with rotavirus, and it was of further interest that 6 of the 20 had two rotavirus infections associated with diarrhea occurring at least 2 months apart. None of 154 diarrheal samples from separate episodes was found to contain Norwalk viral antigens when studied by RIA. ${ }^{\circ}$

Seven samples from the subset of 79 diarrheal samples from eleven cohort children were positive for rotavirus when examined using EM. The same seven samples were also positive for rotavirus using ELISA, as were four additional samples. The results from the use of EM and ELISA in these samples are compared in Table 1; the ELISA was more efficient than EM examination of unconcentrated $10-20 \%$ fecal suspensions for detection of virus.

Stool samples were also available prior to diarrhea from 121 of 183 diarrheal episodes; these
TABLE 2

Frequency of detection of enterovirus, adenovirus, and rotavirus in pre-diarrheal (non-diarrheal) and diartheal specimens from 121 episodes of diarrhea

\begin{tabular}{lccc}
\hline $\begin{array}{c}\text { Virus } \\
\text { detected }\end{array}$ & $\begin{array}{c}\text { No. samples positive* } \\
\text { diarrbeal }\end{array}$ & Diartheal & $\begin{array}{c}\text { Percentage } \\
\text { of total no. } \\
\text { with virus } \\
\text { which were } \\
\text { diarrheal }\end{array}$ \\
\hline $\begin{array}{c}\text { Enterovirus } \\
\text { Poliovirus }\end{array}$ & 3 & 4 & 57 \\
$\begin{array}{l}\text { Other } \\
\text { Adenovirust }\end{array}$ & 49 & 42 & 46 \\
Rotavirus & 6 & 7 & 54 \\
& 3 & 18 & 86
\end{tabular}

* Variability among the relative frequencies of the four group was reflected in the Chi-squared of 10.75 ( 3 d.f.; $P<0.01$; the variability due to rotavirus vs. the combined data of the three remaining groups (Chi-squared $=\mathbf{1 0 . 2 4 ;} 1$ d.f.; $P<0.001$ ) accounted for virtually an of the variability.

$t$ Viruses isolated in cell culture; typing among enteroviruse not done except for polio.

samples were collected on the average of 6.3 days before diarrhea (range 1-43 days). The frequency of detection of poliovirus, enterovirus, adenovirus and rotavirus was tabulated for these 121 episodes and the frequency of isolation was compared between the non-diarrheal (pre-diarrheal) specimens and the acute diarrheal specimens (Table 2). Rotavirus was detected significantly more often during diarrhea than prior to diarrhea; such a difference was not observed for the other viruses combined.

The mean age of the infants and children at the time of diarrhea associated with rotavirus was 15 months with a range of 3-30 months. The median age at the time of rotavirus diarrhea was 14 months. The estimated incidence of rotavirus diarrhea by age is given in Table 3 . The variability in incidence observed among the 6-month age groups was chiefly accounted for by the higher incidence in the 6- to 18-month age groups when compared with all other age groups combined.

There was no striking seasonal pattern in the occurrence of diarrhea associated with rotavirus. The 26 episodes identified occurred between May 1964 and April 1967. These cases were examined by month of occurrence irrespective of year, and one or more rotavirus episodes were observed each month with the exception of June. Four or 5 cases of rotavirus diarrhea were observed in the months of April, October, and December, thus accounting for $50 \%$ of the total. 
TABLE 3

Minimum estimated incidence by age of rotavirus diarrhea in 24 infants and young children based on 183 episodes of diarrhea not associated with bacterial enteric pathogens or acute parasitic infection

\begin{tabular}{|c|c|c|c|c|}
\hline $\begin{array}{c}\text { Age } \\
\text { group }\end{array}$ & $\begin{array}{c}\text { Age } \\
\text { (montbs) }\end{array}$ & $\begin{array}{l}\text { No. } \\
\text { episodes } \\
\text { studied }\end{array}$ & $\begin{array}{c}\text { No. } \\
\text { associated } \\
\text { with } \\
\text { rotavirus }\end{array}$ & $\begin{array}{l}\text { Incidence* } \\
\text { (no. episodes } \\
\text { rotavirus } \\
\text { diarrhea/ } \\
\text { child// } \\
6 \text { months) } \\
\end{array}$ \\
\hline I & $0-6$ & 27 & $2 \dagger$ & 0.08 \\
\hline II & $6-12$ & 39 & 7 & 0.29 \\
\hline III & $12-18$ & 44 & 10 & 0.42 \\
\hline IV & $18-24$ & 33 & 3 & 0.12 \\
\hline V & $24-30$ & 22 & 4 & 0.17 \\
\hline \multirow[t]{2}{*}{ VI } & $30-36$ & 18 & 0 & 0 \\
\hline & Totals & 183 & 26 & - \\
\hline
\end{tabular}

- For total duration of study the minimum estimated incidence was $1.08 \mathrm{cases} / \mathrm{child} / 3$ years. Observed variability in incidence

5 d.i. $\stackrel{P}{P}<0.001$ ) was accounted for chiefly by groups II and III when compared with the four other groups (Chi-squared c III when compared with the

$t$ These two episodes were from the same child at ages 3 and 6 months; thus for statistical comparison, these were considered to be one episode.

Six (23\%) of the 26 rotavirus diarrhea episodes were associated with dehydration, and one patient required hospitalization because of dehydrating illness. Both vomiting and dehydration were significantly more frequent in rotavirus diarrhea compared to all remaining diarrheal episodes among the same group of children (Table 4). In this comparison $15,4 \%$ of total remaining episodes were associated with vomiting and $1.6 \%$ with dehydration, and thus, dehydration was approximately 14 times and vomiting almost 4 times more frequent among patients with known rotavirus diarrhea. In those children with rotavirus diarrhea on two occasions, disease during the second episode did not appear to be less severe than illness observed during the first episode. The mean age of children with dehydrating rotavirus illness was 16 months with a range of 14-21 months.

\section{DISCUSSION}

Rotavirus accounted for $14.2 \%$ of selected diarrheal episodes from which no other etiologic agent could be associated in a small population of infants and young children living in rural Guatemala. Twenty of the 24 children studied had at least one diarrheal episode associated with rotavirus. ELISA was successfully used in the
TABLE 4

Frequency of vomiting and dehydration in diarrheal illness among 24 infants and young children during the first 3 years of life

$\left.\begin{array}{cccc}\hline \multirow{2}{*}{\begin{array}{c}\text { Identification } \\
\text { of episodes }\end{array}} & \begin{array}{c}\text { No. of } \\
\text { episodes }\end{array} & \begin{array}{c}\text { Vomiting } \\
(\%)\end{array} & \begin{array}{c}\text { Dehydration } \\
(\%)\end{array} \\
\hline \text { Rotavirus diarrhea } & 26 & 15(58) \\
\text { All other diarrhea* } & 319 & 49(15.4)\end{array}\right\}$\begin{tabular}{c}
$6(23)$ \\
\hline
\end{tabular}

* Of these 319 episodes, stools from only 157 episodes were tested for rotavirus; the remainder was associated with bacterial enteric pathogens (approximately $30 \%$ ), acute parasitic infecenteric pathogens approximately $30 \%$, acute parasitic iniec-
tions (approximately $12 \%$ ), oc was unavailable for laboratory study (approximately $5 \%$ ). $\dagger P<0.0001$.

detection of rotavirus antigen and appeared to be somewhat more sensitive than EM examination of unconcentrated specimens. Other viruses isolated around and during these episodes of diarrhea ( poliovirus, non-typed enterovirus, and adenovirus) did not appear to be etiological agents associated with the diarrheal illness itself.

The incidence of approximately 1.1 rotavirus diarrheal episodes per child during the first 3 years of life is an estimate based on selected diarrheal episodes excluding those associated with bacterial or parasitic pathogens (approximately $42 \%$ ) and those from which stools were unavailable for study (approximately 5\%). Thus, the true incidence may in fact be higher than this estimate. In addition, the absence of detectable Norwalk viral gastroenteritis in the study population is consistent with the observation of acquisition of antibody to this virus later in life, as observed in a study in the United States. ${ }^{10}$

Rotavirus was found to be associated with diarrhea in children from 3-30 months of age in the survey of 24 children during approximately the first 3 years of life. It is of interest that this Guatemalan population was breast-fed exclusively for 4-6 months at which time supplements were begun; complete weaning was generally effected between 18 and 36 months.' No conclusions can be made, however, regarding the protective effect of breast milk against rotavirus diarrhea because of the lack of a comparable bottle-fed control group along with quantitative antibody measurement.

In temperate climates there is a striking seasonality associated with rotavirus diarrhea, and a Iarge proportion of cases occur during the cooler 
months of the year. ${ }^{11}$ The striking seasonal incidence observed in temperate climates was not seen in the semi-tropical country of Guatemala.

It was of particular interest that among the 24 infants and young children surveyed, six had rotavirus diarrhea on two occasions separated by at least 2 months. Evidence has recently been presented for at least two human rotavirus serotypes based on the use of immunofluorescence, immune electron microscopy, and complement fixation techniques 12' 14 Enzyme-linked immunosorbent assay also has been used recently to identify human rotavirus types 1 and 2 , and preliminary study of the strains from sequential infections reported here indicates that rotaviral disease was not caused on two occasions by the same serotype. ${ }^{14}$

Although rotavirus was only associated with approximately $14 \%$ of selected diarrheal episodes in this survey, it accounted for a large proportion of severe diarrheal illness as defined by vomiting and dehydration. Rotavirus infection was associated with over $50 \%$ of the dehydrating diarrheal illness which occurred in this group of 24 children during the first 3 years of life. Also vomiting was almost four times more common among patients with rotavirus diarrhea compared to all other diarrheal episodes. This association of rotavirus with more severe diarrheal illness is in contrast to illness caused by other enteric agents. In summary, the application of newer technologies to these valuable specimens collected and carefully stored over 10 years ago is aiding in placing rotavirus into perspective regarding its importance in traditional societies of the less developed countries.

\section{ACKNOWLEDGMENTS}

We thank Ms. Bertha Garcia for her excellent coordination of field operations and Dr. David W. Ailing for the statistical analysis. We also thank Ms. Olga Roman, Ms. Palmina Dardón, and Ms. Catalina Mons6n, nurses at the village of Santa Maria Cauqué, for collecting specimens; Mr. Raúl Fernandez (INCAP), Mr. 011egario Pellecer (INCAP), Mr. Roberto Rosales (INCAP), and Ms. Barbara Barbour ( $\mathrm{NIH}$ ) for technical assistance in these studies; and Ms. Julie Paolella for assistance in the preparation of this manuscript.

\section{REFERENCES}

1. Editorial, 1975. Rotaviruses of animals and man. Lancet, 1: 257-259.

2. Editorial, 1977. Rotavirus gastroenteritis. Br. Med. J., 2: 784-785.

3. World Health Organization, 1973. Mortality due to diarrheal diseases in the world. $W H O$ Weekly Epidemiological Record, 48: 409-412.

4. Mata, L., 1978. The Children of Santa Maria Care que. A Prospective Study of Health and Growth. MIT Press, Cambridge, Mass.

5. Mata, L. J., Urrutia, J. J., and Lechtig, A., 1971. Infection and nutrition of children of a low socioeconomic rural community. Am. J. Clin. Nutr., 24: 249-289.

6. Mata, L. J., Mejicanos, M. L., and Jimenez, F., 1972. Studies on the indigenous gastrointestinal flora of Guatemalan children. Am. J. Clin, Nutr., 25: 1380-1390.

7. Yolken, R. H., Kim, H. W., Clem, T., Wyatt, R. G., Kalica, A. R., Chanock, R. M., and Kapikian, A. Z., 1977. Enzyme-linked immunosorbent assay (ELISA) for detection of human reovirus-like agent of infantile gastroenteritis. Lancet, 2: 263-267.

8. Yolken, R. H., Wyatt, R. G., and Kapikian, A. Z., 1977. ELISA for rotavirus. Lancet, 2: 819.

9. Greenberg, H. B., Wyatt, R. G., Valdesuso, J., Kalica, A. R., London, W. T., Chanock, R. M., and Kapikian, A. Z., 1978. Solid phase microtiter radioimmunoassay for detection of the Norwalk strain of acute nonbacterial epidemic gastroenteritis virus and its antibodies. J. Med. Viral., 2: 97-108.

10. Kapikian, A. Z., Greenberg, H. B., Cline, W. L., Kalica, A. R., Wyatt, R. G., James, H. D., Jr., Lloyd, N. L., Chanock, R. M., Ryder, R. W., and Kim, H. W., 1978. Prevalence of antibody to the Norwalk agent by a newly developed immune adherence hemagglutination assay. J. Med. Viral. (In press.)

it. Wyatt, R. G., Kalica, A. R., Mebus, C. A., Kim, H. W., London, W. T., Chanock, R. M., and Kapikian, A. Z., 1978. Reovirus-like agents ( rotaviruses) associated with diarrheal illness in animals and man. Pages 121-145 in M. Pollard, ed., Perspectives in Virology, 10, Raven Press, N.Y.

12. Zissis, G., and Lambert, J. P., 1978. Different serotypes of human rotaviruses. Lancet, 1: 38-39

13. Thouless, M. E., Bryden, A. S., and Flewett, T. H., 1978. Serotypes of human rotavirus. Lancet, 1: 39.

14. Yolken, R. H., Wyatt, R. G., Zissis, G., Brandt, C. D., Rodriguez, W. J., Kim, H. W., Parrott, R. H., Urrutia, J. J., Mata, L., Greenberg, H. B., Kopikian, A. Z., and Chanock, R. M., 1978. Epidemiology of human rotavirus types 1 